\title{
Association mapping of drought tolerance-related traits in barley to complement a traditional biparental QTL mapping study
}

\author{
Magdalena Wójcik-Jagła ${ }^{1}\left[\right.$ [D $\cdot$ Anna Fiust ${ }^{1} \cdot$ Janusz Kościelniak $^{1} \cdot$ Marcin Rapacz $^{1}$
}

Received: 3 April 2017 / Accepted: 27 September 2017 / Published online: 25 October 2017

(C) The Author(s) 2017. This article is an open access publication

\begin{abstract}
Key message Association mapping of drought-related traits in barley was used to increase the density of existing QTL maps without recreating mapping populations. Abstract We used 109 spring barley genotypes exhibiting high or low drought tolerance to elucidate the associations between diversity array technology sequencing (DArTseq) and single nucleotide polymorphism (SNP) markers and various physiological parameters related to plant responses to drought conditions. The study was performed in controlled conditions (growth chambers), drought tolerance was phenotyped in the four-leaf seedlings. We identified 58 associations including 34 new markers (i.e., 16 DArTseq and 18 SNP markers). The results for three markers were consistent with the data obtained in an earlier traditional biparental QTL mapping study. The regions neighboring markers on linkage group $2 \mathrm{H}$ contained the highest number of significant marker-trait associations. Five markers related to the photosynthetic activity of photosystem II were detected on chromosome $4 \mathrm{H}$. The lowest number of associations were observed for the sequences neighboring DArT markers on linkage group $6 \mathrm{H}$. A chromosome $3 \mathrm{H}$ region related to water use efficiency and net photosynthesis rate in both biparental QTL, and association study, may be particularly valuable,
\end{abstract}

Communicated by Peter Langridge.

Electronic supplementary material The online version of this article (doi:10.1007/s00122-017-2994-1) contains supplementary material, which is available to authorized users.

Magdalena Wójcik-Jagła

magdalena.p.wojcik@gmail.com

1 Department of Plant Physiology, University of Agriculture in Krakow, Podłużna 3, 30-239 Kraków, Poland as these parameters correspond to the ability of plants to remain highly productive under water deficit stress. Our findings confirm that association mapping can increase the density of existing QTL maps without recreating mapping populations.

\section{Introduction}

Analyzing quantitative traits is challenging, which makes these traits difficult to improve via plant breeding. Therefore, for many years, research tended to focus on the identification of single genes with the biggest effects on the overall phenotype until two methods enabling investigations of quantitative traits have been developed-genetic linkage-based biparental QTL mapping and association mapping. Both of these approaches rely on the analysis of the strength of the relationships between genetic markers and phenotypic traits (Korte and Farlow 2013). However, while QTL mapping uses correlations between the sharing of chromosomal regions among relatives and their trait similarities (as it is a highly controlled experiment, in which the level of kinship is known), association mapping directly combines the genotype and phenotype in a "natural" experiment, where the relationships between the objects are not controlled (Myles et al. 2009; Purcell et al. 2003).

Association mapping, which is also called linkage disequilibrium (LD) mapping or population mapping, is based on the non-accidental associations of alleles at different loci on the same chromosome (Mackay and Powell 2007; Flint-Garcia et al. 2003). In contrast to QTL analyses, association mapping uses plant materials that are not closely related (i.e., natural populations) (Korte and Farlow 2013). Using LD to map quantitative traits is more challenging than the standard QTL analysis protocol. 
However, there are potential advantages, including that it enables a more precise determination of the location of a QTL associated with a specific trait. Furthermore, association mapping is very effective for studying species that are difficult to cross or clone, or those with a long reproduction time (Nordborg and Weigel 2008). Investigations based on LD analyses and association mapping have been conducted for many species, including monocots such as corn, barley, rice and sorghum (Zhu et al. 2008; Korte and Farlow 2013). In barley plants, associations have been detected between genetic markers and the following phenotypic traits: flowering time (Stracke et al. 2009), yield (Kraakman et al. 2004; Gawenda et al. 2015), disease resistance (Roy et al. 2010; Massman et al. 2011), drought tolerance (Varshney et al. 2012), salinity tolerance (Fan et al. 2016) and freezing tolerance (Rapacz et al. 2010a; Visioni et al. 2013). An essential flaw of association mapping is that there is a risk of obtaining false positive results (Pritchard et al. 2000) where LD is a result of existence of subpopulations, not true associations (Cardon and Bell 2001). This is a result of using an open, natural experimental system, in which it is hard to find out about the frequency of recombination events (Myles et al. 2009). However, there are several methods involving analyses of the population structure that can be used to ensure the obtained results correspond to real effects (Porras-Hurtado et al. 2013).

Nowadays the best results are obtained by combining association mapping and biparental QTL mapping. Association mapping in some particular cases may be insufficient to detect an association (low frequency alleles, QTL with small effects), and then biparental QTL mapping can be used as a way to control the population structure and recombination frequency (Myles et al. 2009). There have been statistical methods developed to connect those two approaches, namely joint linkage-association mapping as first (Wu and Zeng 2001; Meuwissen et al. 2002), and, more recent and complex, nested association mapping (NAM) (Yu et al. 2008; McMullen et al. 2009).

The aim of this study was to thoroughly investigate the genetic determinants of drought tolerance in Polish barleys by combining two approaches to studying quantitative traits. In a previous study, we conducted a QTL analysis on two barley $\mathrm{F}_{2}$ populations (Wójcik-Jagła et al. 2013). To complement this approach and confirm previously obtained results in the present study, we performed an association mapping experiment using a population of barley cultivars and advanced breeding materials (Fig. 1). The second and more practical purpose of this study was to saturate the QTL regions revealed in our previous study (Wójcik-Jagła et al. 2013) with new DArTseq and SNP markers.

\section{Materials and methods}

\section{Plant materials}

Barley materials consisted of advanced breeding lines and cultivars grown by the following two breeding companies: HR Strzelce Ltd. group IHAR (located in Strzelce, Poland-527 genotypes) and HR Danko sp. z o.o. (located in Choryń, Poland-180 genotypes). We also used doubledhaploid lines (506 genotypes) developed by HR Strzelce from ten crossings between "Suweren" (drought-tolerant cultivar) and other cultivars with different origins.

\section{Selection of genotypes for association studies}

The selection of barley genotypes of potential high and low drought tolerance was performed basing on specific sequence-tagged site markers and simple sequence repeat markers derived from diversity array technology (DArT) markers (Fiust et al. 2015). The markers were associated with two QTL regions reported in Wójcik-Jagła et al. (2013), related to chlorophyll $a$ fluorescence parameters, as well as with additional seven regions significant in the preliminary simple marker regression analysis, related to electrolyte leakage (EL), water content (WC), net photosynthesis rate $\left(P_{\mathrm{n}}\right)$, and rate of PSII quantum efficiency related to the quantum efficiency of $\mathrm{CO}_{2}$ assimilation ( $\left.\Phi \mathrm{PSII} / \Phi \mathrm{CO}_{2}\right)$.

The youngest leaves on field-grown plants were collected just before heading, after which they were frozen in liquid nitrogen and lyophilized (Freezone 4.5, Labconco, Kansas City, MO, USA). The lyophilized leaves were ground to powder, from which DNA was extracted using the GeneJET Plant Genomic DNA Purification Mini Kit (Thermo Scientific, Waltham, USA). The quantity and quality of purified DNA were assessed using the Q500 spectrophotometer (Quawell, San Jose, USA). The DNA from the 1213 tested genotypes was then used for polymerase chain reaction (PCR) amplifications. The PCRs were conducted with 19 primer combinations (Table 1). Each PCR consisted of the following components: $1 \times$ PCR buffer with $\left(\mathrm{NH}_{4}\right)_{2} \mathrm{SO}_{4}$ (Thermo Scientific), $250 \mathrm{nM}$ each primer, $3.5 \mathrm{mM} \mathrm{MgCl}{ }_{2}$, $200 \mathrm{mM}$ dNTP, $0.4 \mathrm{U}$ Taq polymerase (Thermo Scientific), 20 ng DNA, and $400 \mu \mathrm{M}$ spermidine (Sigma-Aldrich, Darmstadt, Germany). The marker sequences were amplified in a Labcycler (SensoQuest, Göttingen, Germany) using one of three temperature profiles depending on primer melting temperatures (Table 2).

\section{Plant growth and drought treatment}

Based on the molecular selection results, 109 lines exhibiting low or high drought tolerance were chosen (Online Resource 1). Seeds of these genotypes were sown in pots 


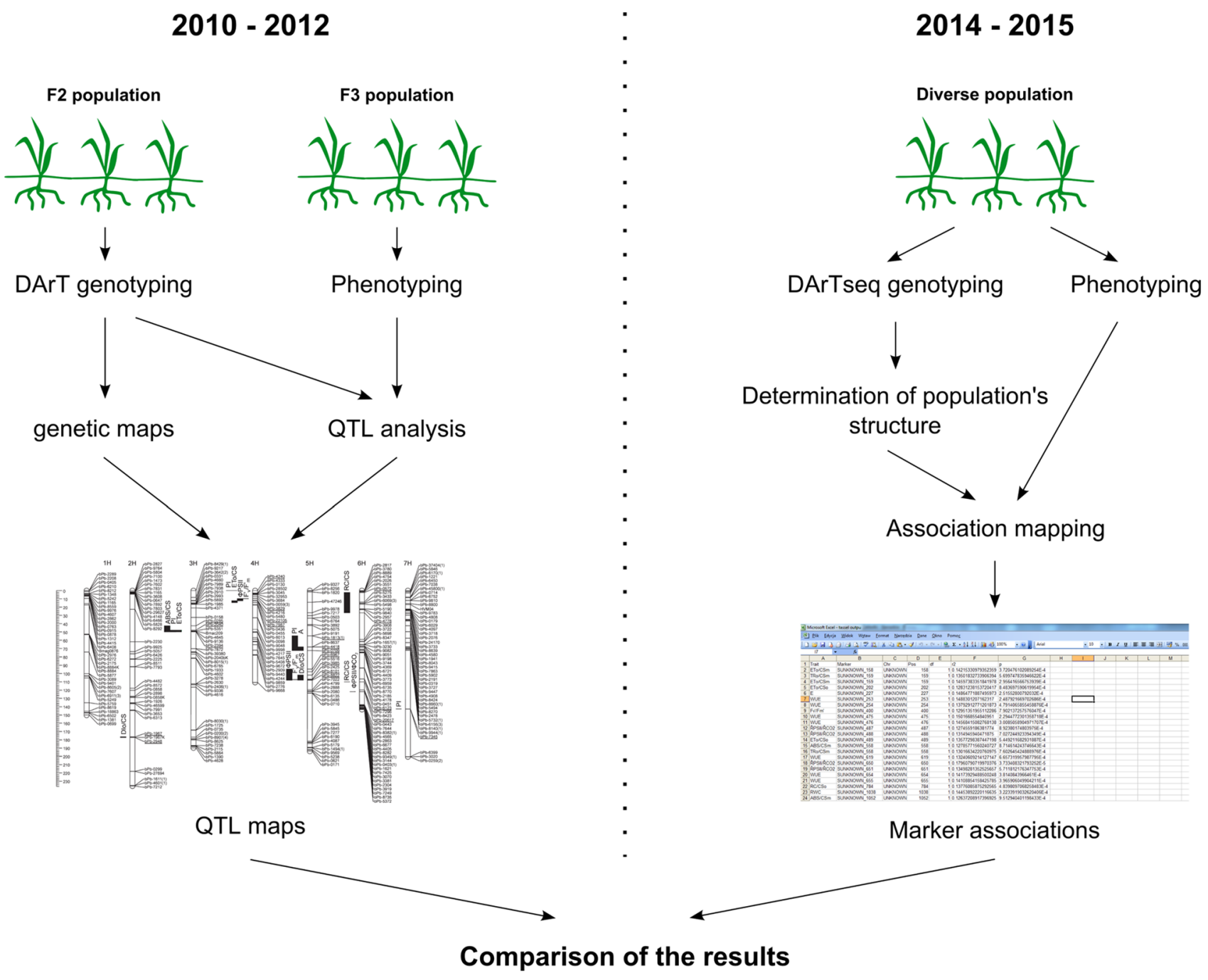

Fig. 1 The experiments' outline. Results from the 2010-2012 experiments were published in Wójcik-Jagła et al. (2013). Experiments from the years 2014-2015 and their results are described in the present study

( $5 \mathrm{dm}^{3}$, one genotype per pot and one pot per genotype, 12 seeds per genotype) filled with a mixture of universal garden soil substrate (Ekoziem, Jurkow, Poland) and sand $(1: 1, \mathrm{v}: \mathrm{v})$ and put in growth chambers in a fully randomized order. Genotypes were sown sequentially (10 genotypes per day). The plants were grown incubated in $25^{\circ} \mathrm{C} / 17^{\circ} \mathrm{C}$ (day/ night), with a 14-light/10-h dark photoperiod (irradiance: $400 \mu \mathrm{mol} \mathrm{m}{ }^{-2} \mathrm{~s}^{-1}$; HPS lamps, SON-T+ AGRO, Philips, Brussels, Belgium). The plants were watered as required and treated once a week with Florovit multipurpose fertilizer (Inco, Góra Kalwaria, Poland) according to the manufacturer's instructions. The soil water content (WC) was maintained at $70 \%$ maximum water capacity (MWC) until plants reached the four-leaf stage by adding the required amount of water based on daily weight measurements. Water was subsequently withheld from drought-treated plants for 10 days, during which the MWC gradually decreased to $21 \%$ according to the HydroSense Soil Water Content Measurement System (Campbell Scientific, Thuringowa Central, Australia). Under these conditions, leaves of all genotypes exhibited symptoms of turgor loss. Soil WC was kept at $70 \%$ MWC in the not treated (control) plants until the measurements of the physiological parameters.

\section{Genotyping}

We extracted DNA from the fourth leaf (i.e., youngest) of the selected 109 genotypes, and assessed the DNA quality using the same kit and quality assessment procedure described above. The DNA samples were then screened using DArT sequencing (DArTseq) technology (http://www. diversityarrays.com/dart-application-dartseq), which combines DArT technology with next-generation sequencing. 
Table 1 DArT-derived markers used for the genomic selection for drought tolerance, type of marker, amplification profile name (see Table 2) and primer sequences

\begin{tabular}{|c|c|c|c|}
\hline Marker & $\begin{array}{l}\text { Marker type (amplification } \\
\text { profile) }\end{array}$ & Forward $\left(5^{\prime}-3^{\prime}\right)$ & Reverse $\left(5^{\prime}-3^{\prime}\right)$ \\
\hline bPb-1312 & STS (52) & TGAAACATCGAAACCCACAA & СТCCATTCCTCTGGCTATGC \\
\hline bPb-8884 & STS (55) & CATGTGCAAACTGTCCCAAC & CTAGCAGCAGCAAGTGCATC \\
\hline bPb-1967 & STS (55) & AGGTTTTCAAGCAGCTACGC & CAAGAAAGCAGATGGCACAA \\
\hline bPb-1967b & STS (55) & TTGCAGAAGGCGGATAATTC & TTTCGGGCACTGATTTCAAC \\
\hline bPb-0858 & STS (58) & GGCAGGTACACCGCCACT & TCAGAGCACACGTATGCAGAT \\
\hline bPb-2040b & STS (55) & CCATAAAGTTAAGAATTTGCCTCA & GCAACTCACACCССТTCTGT \\
\hline bPb-6399 & STS (55) & TGCACAGCCTAAAAGAATCG & TGTTGGCACAGCATGTTAGC \\
\hline bPb-6450 & STS (52) & ACGCCCAAGTCACAAATCTT & GGTCCAGTTCCTGTTCTTGG \\
\hline bPb-0994 & STS (52) & CCACCCCAATGTGTTCTCTC & TGCAGGCGAAAATTGTTGTA \\
\hline bPb-1051 & STS (55) & CGTCCCCATGATCCTTTTT & GCAGGCTATTTTGTGGCTTT \\
\hline bPb-1051b & STS (55) & CGGGAAGCTCTATCACTCGT & TGATATGTGCAGCGTCCATT \\
\hline bPb-8589 & STS (55) & AGCTCTCTGTAGATCAGGTTGC & CGACAACGGGAATGGAAC \\
\hline bPb-9645 & STS (55) & CATGTCAAAAGCTATGGATGC & CTTGCCCTCTCTCGTCAAAC \\
\hline bPb-6735 & STS (52) & TCAGGCATCTGCAATTTTTG & TTCGGTCCTTCTTGCATACC \\
\hline bPb-6721 & STS (55) & GGAAAAACAAAACTGAGGCAAA & GTGGATTGTGAGGCCGATT \\
\hline bPb-3908 & STS (52) & TCGAGATGCATCAGACTTTCA & TTCGGTCCTTCTTGCATACC \\
\hline bPb-7786 & STS (52) & GCTGGAGACTTGGAGGACAG & TGGTTATTACCACAACCAGA \\
\hline Bmag0876 & SSR (55) & AATTAAAAGCTGAAGGTCTACA & CTGCTCCTTCAACGACTAC \\
\hline Bmac209 & SSR (55) & ATGCCTGTGTGTGGACCAT & CTAGCAACTTCCCAACCGAC \\
\hline scssr02503 & SSR (55) & AACAACTTTTGATGGACAAACC & TGTCTTTTCTTTTTGCTCTGC \\
\hline
\end{tabular}

Table 2 Amplification profiles

\begin{tabular}{|c|c|c|c|c|c|}
\hline $\begin{array}{l}\text { Cycle signature } \\
\text { Parameters }\end{array}$ & $\begin{array}{l}52 \\
\text { temp. }\left({ }^{\circ} \mathrm{C}\right)\end{array}$ & $\begin{array}{l}55 \\
\text { temp. }\left({ }^{\circ} \mathrm{C}\right)\end{array}$ & $\begin{array}{l}58 \\
\text { temp. }\left({ }^{\circ} \mathrm{C}\right)\end{array}$ & Time (s) & $\begin{array}{l}\text { Number } \\
\text { of cycles }\end{array}$ \\
\hline Pre-denaturation & 95 & 95 & 95 & 120 & 1 \\
\hline Denaturation & 94 & 94 & 94 & 45 & 7 \\
\hline Primer linkage & 59 & 62 & 65 & 45 & \\
\hline Polymerase linkage & 72 & 72 & 72 & 45 & \\
\hline Denaturation & 94 & 94 & 94 & 45 & 41 \\
\hline Primer linkage & 52 & 55 & 58 & 45 & \\
\hline Polymerase linkage & 72 & 72 & 72 & 45 & \\
\hline Annealing & 72 & 72 & 72 & 600 & 1 \\
\hline
\end{tabular}

The polymorphism was identified in a 0/1 system, which indicates either the presence or absence of a marker.

\section{Phenotyping}

Due to diurnal changes observed usually for many of measured parameters all the measurements were made at midday (between 11 a.m. and 2 p.m.). Photosystem II (PSII) activity, gas exchange, relative WC (RWC), and electrolyte leakage were measured in plants with $21 \%$ MWC. The PSII photochemical activity was measured in the middle part of the second leaf using eight replicates (leaves from 8 different plants randomly chosen out of 12 growing in the same pot) per genotype. We used two measurement systems as previously described, namely the modulated fluorescence system FMS2 (Hansatech, Kings Lynn, UK) and the fast chlorophyll fluorescence induction kinetics fluorimeter Handy PEA (Hansatech, Kings Lynn, UK) (Rapacz et al. 2010a, b, Wójcik-Jagła et al. 2013). The FMS2 system was used to calculate the following parameters: PSII antenna trapping efficiency $\left(F_{v}^{\prime} / F_{m}^{\prime}\right)$, photochemical light energy quenching coefficient $\left(q_{\mathrm{P}}\right)$, and quantum yield of electron transport in PSII [i.e., $\Phi$ PSII $\left.=\left(F_{m}^{\prime}-F_{s}\right) / F_{m}^{\prime}\right]$ (Genty et al. 1989). The Handy PEA was used to analyze parameters based on the theory of energy flow in PSII, and involved the OJIP test (Strasser et al. 2000). The fluxes in the energy absorbed 
by PSII antennae (ABS), trapped in PSII reaction centers (TR), used for electron transport (ET), and dissipated from PSII, and dissipated from PSII (DI), as well as the maximum number of active reaction centers (RC) were calculated per excited leaf cross section (CS) at $t=0\left(\mathrm{CS}_{0}\right)$ or at the $t$ of $F_{\mathrm{m}}\left(\mathrm{CS}_{\mathrm{m}}\right)$. The energy fluxes per active PSII RC were also considered. Additionally, the overall PSII photochemical performance index for equal absorption $\left(\mathrm{PI}_{\mathrm{ABS}}\right)$ was calculated together with the more traditional performance index of energy trapped in PSII $\left(F_{\mathrm{v}} / F_{\mathrm{m}}\right)$. The middle part of the second leaf was used to measure gas exchange parameters with a Ciras-3 infrared gas analyzer (PP Systems, Hitchin, UK) and a Parkinson leaf chamber (PLC6) as described elsewhere (Rapacz et al. 2010a). The controlled environmental conditions were as follows: $400 \mu \mathrm{mol} \mathrm{mol}^{-1} \mathrm{CO}_{2}, 30 \%$ relative humidity, $500 \mu \mathrm{mol} \mathrm{m}{ }^{-2} \mathrm{~s}^{-1}$ irradiance, and $25^{\circ} \mathrm{C}$ leaf temperature. The following parameters were measured based on gas exchange and chlorophyll fluorescence data for 10 replicates (leaves from 10 different plants randomly chosen out of 12 growing in the same pot): transpiration rate $(E), P_{\mathrm{n}}$, intercellular $\mathrm{CO}_{2}$ concentration $\left(C_{\mathrm{i}}\right)$, stomatal conductivity $\left(g_{\mathrm{s}}\right)$, quantum yield of $\mathrm{CO}_{2}$ assimilation $\left(\Phi \mathrm{CO}_{2}\right)$, water use efficiency (WUE), and $\Phi P S I I / \Phi C C_{2}$. The RWC was measured for the first (i.e., the oldest) leaf for eight replicates (leaves from 8 different plants randomly chosen out of 12 growing in the same pot) per genotype. The samples were weighed (fresh weight; FW), placed in $25-\mathrm{ml}$ closed tubes filled with water, and shaken in darkness for $24 \mathrm{~h}$. Samples were weighed again to determine the turgor weight (TW), after which they were transferred to paper envelopes and incubated at $70{ }^{\circ} \mathrm{C}$ in an air drying chamber (Lumel, Zielona Góra, Poland) for $48 \mathrm{~h}$. The dry weight (DW) of the samples was then measured. The RWC was calculated using the following equation according to Barrs (1968):

$\operatorname{RWC}(\%)=(\mathrm{FW}-\mathrm{DW}) \times(\mathrm{TW}-\mathrm{DW})^{-1} \times 100$.

Membrane integrity was assessed according to electrolyte leakage for eight replicates (leaves from 8 different plants randomly chosen out of 12 growing in the same pot) per genotype. The measurements were conducted with $1-\mathrm{cm}$ cuttings from the middle part of the first (i.e., oldest) leaf as described by Rapacz et al. (2010a).

\section{Determination of population structure}

The physical positions of markers within the QTL regions for drought tolerance in spring barley (Wójcik-Jagła et al. 2013) were identified using the ViroBLAST program (Deng et al. 2007) and genome sequence databases for Morex, Barke, and Bowman cultivars as references. The marker sequences most similar to the contig sequence were considered. Based on the determined physical positions (WójcikJagła et al. 2013), a set of DArTseq and single nucleotide polymorphism (SNP) markers within $5 \mathrm{cM}$ were developed and subjected to association mapping. As the existence of substructures within a population can increase type I error in association analyses (Cardon and Bell 2001) we studied possible relationships between the genotypes using two methods. First, the similarities within the studied set of markers and genotypes were identified according to cluster analyses using the UPGMA method with Dice's similarity coefficient. The structure of the tested datasets was determined, and repetitive results (i.e., identical polymorphism patterns) were eliminated. The analysis was performed using Statistica 10 software (Statsoft, Tulsa, USA). The detailed population structure analysis was completed using the STRUCTURE v. 2.3.4 program (Pritchard et al. 2000). Compared to other software dedicated for population analysis, STRUCTURE can easily manage different types of markers, including SNPs and dominant loci such as DArTseq markers (Porras-Hurtado et al. 2013). The admixture model was chosen with 10,000 cycles and 1000 repeats per cycle. The test was conducted ten times for several subpopulations $(K=1-6)$. The $K$ parameter was determined as described by Evanno et al. (2005).

\section{Association analysis}

The marker-trait associations were determined using the TASSEL program (Ithaca, New York; Bradbury et al. 2007). The following datasets were used for the analysis: genotyping results (0/1 matrix), phenotyping results for drought tolerance-related parameters (numerical), and population structure described above. The genotypic data required a minimum allele frequency of 0.05 . As barley is a selfpollinating plant, the degree of kinship is on a highly controlled level in populations of known origin, such as the one used in this study. Therefore, no correction for kinship was included. In consequence, associations were calculated according to the general linear model, which finds the ordinary least squares solution for each marker-trait association (Bradbury et al. 2007). The threshold probability level was set at 0.001 . An additive data analysis model was used. To retrieve all of the significant effects we decided not to add any additional factors to the linear model. Probability values from the GLM model were adjusted using false discovery rate (FDR) according to the procedure by Benjamini and Hochberg (1995). 


\section{Results}

\section{Genotyping}

The DArTseq genotyping of 109 spring barley lines with diverse drought responses revealed 15,828 specific DArTseq markers, of which 10,652 sequences were localized in defined contigs of Morex, Barke, or Bosman barley varieties. A total of 5153 sequences generated from the DArTseq analysis were not unambiguously assigned to any defined barley genome region. The degree of polymorphism of identified sequences varied in the analyzed population. We determined that 1676 DArTseq sequences were polymorphic in all tested genotypes. The least effective polymorphism assessment based on the allelic readings and the ratio of the genotypes tested (i.e., 73-80\%) was observed for 86 DArTseq sequences. The polymorphism information content (PIC) of 2063 marker sequences was no more than $18 \%$, which indicated the markers were relatively unsuitable for distinguishing between genotypes. We observed that 1649 sequences had the highest PIC within the tested genotypes (i.e., 49-51\%). Additionally, 1005 marker sequences that were absent in most genotypes were identified as the least polymorphic (PIC $\leq 10 \%$ ). The effectiveness of the polymorphism identification within tested genotypes was over $99 \%$.

The tested genotypes also contained 7829 sequences with a SNP. The SNPs were identified based on the following three allelic variants: 0 and 1 (i.e., homozygous allele pattern for the reference/target base variant) and 2 (i.e., heterozygotes presenting with a two-allele pattern). Accordingly, 4541 sequences were identified as homozygous (i.e., $58 \%$ of the total number of sequences).

\section{Phenotyping}

The physiological parameters measured in this study were highly differentiated within the population (Online Resource 2). There were no significant differences between the plants in the control conditions (data not shown). The initial selection of drought tolerant and drought susceptible genotypes by means of molecular markers was quite successful and candidate tolerant genotypes performed better in drought. This difference was statistically significant in the case of key parameters of drought tolerance such as WC, RWC, $P_{\mathrm{n}}$ and $E$. In tolerant group, higher net assimilation rate in drought was thus accompanied by higher RWC which together with higher $E$ suggested additional higher ability to water extraction from the soil. Among the studied parameters the highest differentiation between the genotypes was observed in the case of gas exchange related parameters $\left(P_{\mathrm{n}}, E, g_{\mathrm{s}}, C_{\mathrm{i}}\right.$, WUE) as well as water relations and EL (Fig. 2). Out of all chlorophyllfluorescence related parameters, PI(abs), which characterizes the overall PSII photochemical performance, varied most between genotypes.

\section{Association mapping}

The genotyping data used for association mapping comprised 1001 DArTseq markers and 796 SNP markers located within $5 \mathrm{cM}$ from DArT markers in regions with QTLs for drought tolerance-related parameters. The cluster analysis results did not reveal any subpopulations among the tested genotypes (Fig. 3). Three subpopulations were distinguished with the STRUCTURE program. The first included 26 genotypes, while the second and third subpopulations consisted of 32 and 51 breeding lines, respectively. Five genotypes (i.e., DB07022/1, DB07022/11, J08084/3, J08084/20, and STH34838) were highly likely to belong to more than one subpopulation (Table 3). The population's structure was associated with drought tolerance to some extent. First subpopulation seemed to consist of mostly tolerant, while the third subpopulation-mostly susceptible to drought genotypes. But while the genotypes of the first subpopulation did have the highest level of water in their leaves, they also had the lowest WUE (Online Resource 2).

The association mapping analysis uncovered 58 associations including 34 new markers (i.e., 16 DArTseq and 18 SNP markers). All of the associations were positively evaluated by FDR. The strength of the association between a marker and a phenotypic trait was assessed based on the probability value. The strongest relationship between a marker and a trait was observed for three DArTseq markers (i.e., 3986215, 3272729, and 4789498) as well as three SNP markers (i.e., 3255717, 5249538, and 100002239) (Table 4). Most of these sequences were significantly related to plant water relations parameters (e.g., RWC and WUE). Each of the revealed associations explained $6.97-14.52 \%$ of observed phenotypic variance in the studied traits.

The results for three markers were consistent with the observations of a previous study (Wójcik-Jagła et al. 2013; Table 4). Sequence 3986215 identified at position $141.01 \mathrm{cM}$ on chromosome 2 was associated with many chlorophyll fluorescence-based characteristics of PSII performance in drought-stressed plants, including those related to photosynthetic energy conversion (i.e., ABS, TR, and ET) as well as the RC/CS. This sequence co-localized with the physical positions of markers bPb-0572 $(142.63 \mathrm{cM})$ and $\mathrm{bPb}$ $1051 \mathrm{bK}$ flanking the QTL regions for $q_{\mathrm{P}}$ and RC/CS.

Similarly, marker 3267111 was associated with ФPSII, and was located within $0.53 \mathrm{cM}$ from markers bPb-6048 and bPb-6280 in QPSII.sthf-2H (Wójcik-Jagła et al. 2013). A comparable relationship was detected for markers 100002239 and bPb-8589 (QWC.sthf-5H.2; Wójcik-Jagła 


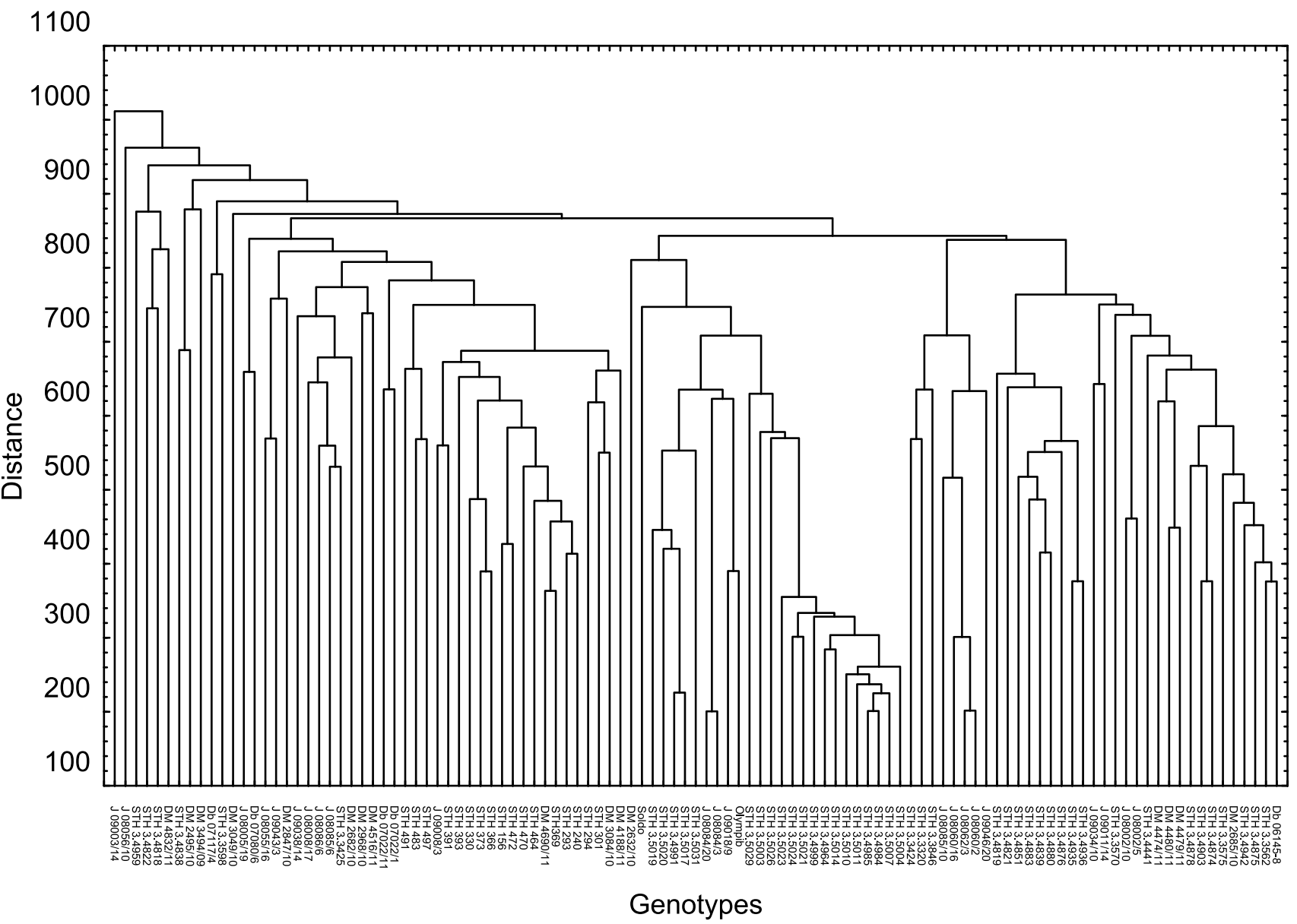

Fig. 2 Results of the cluster analysis of the similarities within the studied set of genotypes using the UPGMA method with Dice's similarity coefficient

et al. 2013) from linkage group $5 \mathrm{H}( \pm 5.89 \mathrm{cM})$. These two markers were correlated with plant water relations parameters (e.g., RWC and WC).

The regions neighboring markers on linkage group $2 \mathrm{H}$ (Table 4) contained the highest number of significant marker-trait associations, particularly the 141.01-148.16 cM region, which included eight markers associated with 13 parameters related mostly to photosynthetic activity of drought-stressed plants. These results are similar to those observed in a previous QTL analysis (Wójcik-Jagła et al. 2013). We also detected a relatively high density of five markers related to PSII photosynthetic activity on chromosome $4 \mathrm{H}$. Furthermore, the $43.34-53.6 \mathrm{cM}$ region of this chromosome was rich in markers associated with parameters related to gas exchange in drought-stressed plants (Table 4). The lowest number of associations was observed for the sequences neighboring DArT markers on linkage group 6H (Table 4).

\section{Discussion}

The idea of combining traditional biparental QTL mapping and association mapping in one analysis was first proposed almost 10 years ago in a review paper written by Myles et al. (2009). This new approach to QTL mapping was quickly implemented by Brachi et al. (2010) and Famoso et al. (2011) who aimed to uncover the genetic determinants of Arabidopsis thaliana flowering time in the field and characterize the genetic architecture of aluminum tolerance in rice, respectively. In these two studies, a traditional QTL analysis of mapping populations derived from biparental crosses was complemented with the association mapping of natural plant accessions. Unlike the study presented herein, these two approaches were designed as complementary from the beginning. The two earlier studies also used mapping populations that were created from selected cultivars of a set of natural accessions subjected to association mapping (Shindo et al. 2005; Zhao et al. 2011). In the present study, 


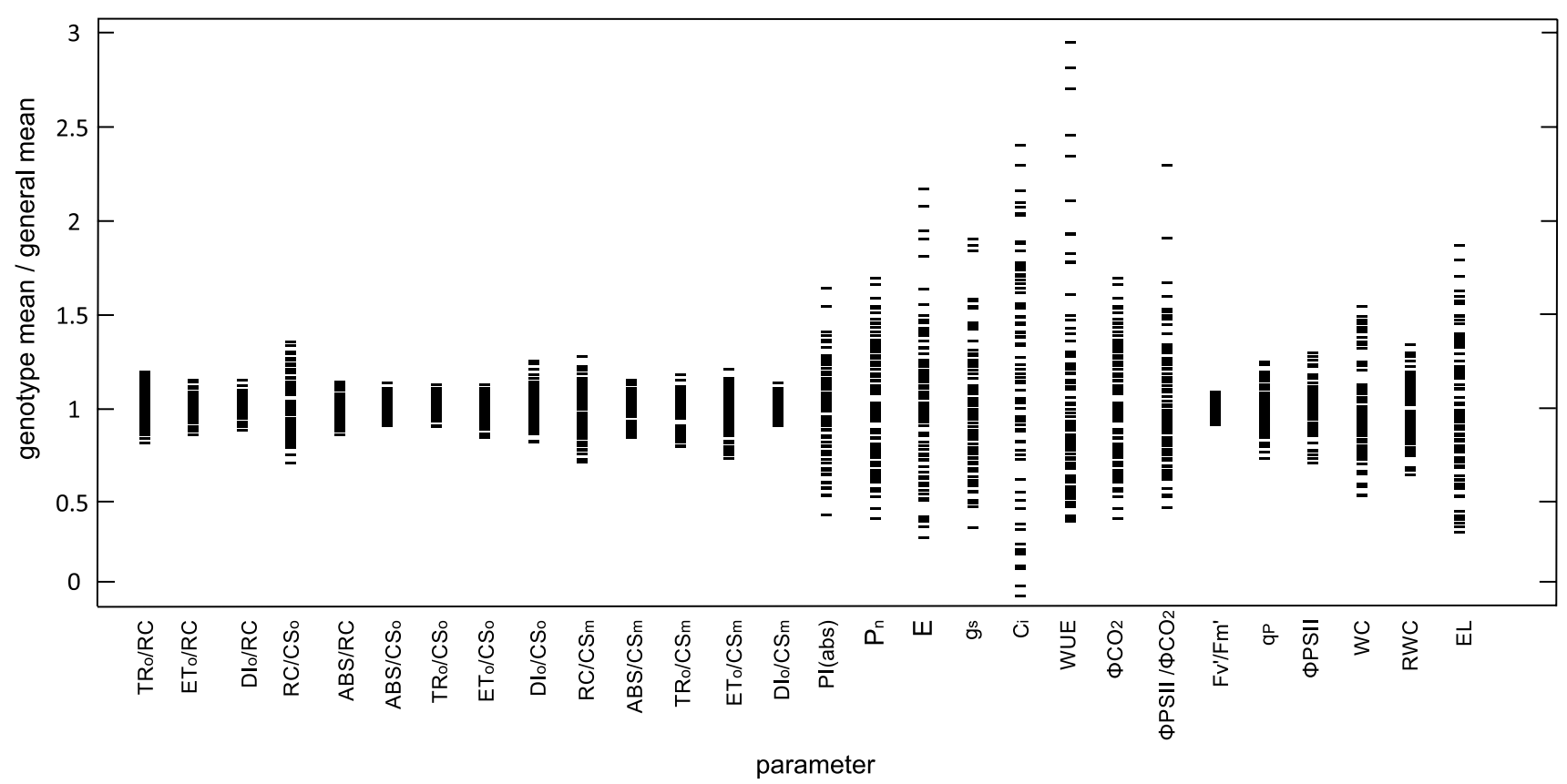

Fig. 3 Variation in measured physiological characteristics of drought response among studied genotypes. Mean values for genotypes are normalized for general means

only one of the four parents included in the previous study (Wójcik-Jagła et al. 2013) was used for association mapping. Additionally, the barley materials used in this study and previously were substantially different (i.e., $F_{2}$ mapping populations for the QTL study and a diverse collection of advanced breeding lines mixed with some cultivars grown in Poland). However, they were also similar because their gene pools were optimized for cultivation under the humid continental climate of Poland.

Combining the results from previous traditional QTL studies and association mapping experiments is likely impossible for materials with different origins/gene pools. Most of the studies involving traditional QTL mapping have involved genetically distant cultivars/breeding lines as parents for the mapping populations to obtain the desired segregation for the studied trait in the progeny (Agarwal et al. 2008). Researchers have used parent genotypes from different continents or even different species (e.g., wild and cultivated barley crossings) (Forster et al. 2000). This fact alone makes combining the results of most existing traditional QTL studies with association mapping results (which are mainly generated for related genotypes) difficult or perhaps even pointless. The procedure of choosing of the parent genotypes for our previous study was different (Wójcik-Jagła et al. 2013), making such a combination possible.

The data for traditional QTL and association mapping experiments have never been combined for parameters related to drought tolerance in spring barley. This approach represents an alternative to the integration of the mapping results in previous barley studies (Alsop et al. 2011; Szúcs et al. 2009). Our experimental approach combines two independent genetic analyses of drought tolerance conducted with two sets of barley accessions. The use of DArTseq and SNP markers for mapping regions with QTLs considered responsible for drought tolerance has enabled a more detailed characterization of the drought response-related regions of the barley genome.

Although the most common approach to association mapping is genome-wide association study (GWAS), for the sake of our study and its practical aim of saturating already existing QTL regions related to drought tolerance in barley, we performed association mapping limited to those regions. A similar approach, resulting from a need to search for associations within previously selected candidate genes, was used by several researchers (Harjes et al. 2008; Zheng et al. 2008; Holliday et al. 2010; Caniato et al. 2014). Immense number of markers obtained only for the chosen regions and wide chromosomal coverage of these QTLs (Wójcik-Jagła et al. 2013) were enough to determine the population's structure and marker-trait associations.

The obtained population's structure was related to some of the drought-tolerance parameters. One of the probable reasons for this is that the selection of the plant material for the association study was done by means of markers proposed in Fiust et al. (2015). The subpopulations obtained by STRUCTURE were not consistent with the criteria used for selecting the mapping population, though. The first and third subpopulation contained majority of tolerant or susceptible 
Table 3 Population's structure obtained using STRUCTURE software

\begin{tabular}{|c|c|c|c|c|c|}
\hline \multirow[t]{2}{*}{ No. } & \multirow[t]{2}{*}{ Genotype } & \multicolumn{3}{|c|}{$\begin{array}{l}\text { Probability that the genotype } \\
\text { belongs to subpopulation }\end{array}$} & \multirow[t]{2}{*}{ Subpopulation } \\
\hline & & $1 \mathrm{~S}(\mathrm{p})$ & $2 \mathrm{~S}(\mathrm{p})$ & $3 \mathrm{~S}(\mathrm{p})$ & \\
\hline 1 & DB06145-98 & 0 & 0 & 0.999 & 3 \\
\hline 2 & DM4832/11 & 0.105 & 0.227 & 0.668 & 3 \\
\hline 3 & DM4188/11 & 0.001 & 0.358 & 0.642 & 3 \\
\hline 4 & STH35004 & 1 & 0 & 0 & 1 \\
\hline 5 & STH35021 & 1 & 0 & 0 & 1 \\
\hline 6 & STH35026 & 1 & 0 & 0 & 1 \\
\hline 7 & STH240 & 0 & 1 & 0 & 2 \\
\hline 8 & DM3494/09 & 0.106 & 0.7 & 0.194 & 2 \\
\hline 9 & DM2847/10 & 0.536 & 0.372 & 0.092 & 1 \\
\hline 10 & DM4479/11 & 0 & 0.04 & 0.96 & 3 \\
\hline 11 & STH35007 & 1 & 0 & 0 & 1 \\
\hline 12 & STH35023 & 1 & 0 & 0 & 1 \\
\hline 13 & STH34942 & 0 & 0 & 1 & 2 \\
\hline 14 & STH393 & 0 & 1 & 0 & 2 \\
\hline 15 & DM3049/10 & 0.166 & 0.009 & 0.826 & 3 \\
\hline 16 & $\mathrm{~J} 08002 / 5$ & 0.001 & 0.051 & 0.948 & 3 \\
\hline 17 & DM4480/11 & 0.001 & 0 & 0.999 & 3 \\
\hline 18 & STH35010 & 1 & 0 & 0 & 1 \\
\hline 19 & STH35024 & 1 & 0 & 0 & 1 \\
\hline 20 & STH470 & 0 & 1 & 0 & 2 \\
\hline 21 & STH391 & 0 & 0.909 & 0.091 & 2 \\
\hline 22 & $\mathrm{~J} 08002 / 10$ & 0.072 & 0.05 & 0.878 & 3 \\
\hline 23 & DM4516/11 & 0.001 & 0.67 & 0.329 & 2 \\
\hline 24 & DM2682/10 & 0 & 0.703 & 0.297 & 2 \\
\hline 25 & STH35011 & 1 & 0 & 0 & 1 \\
\hline 26 & STH35029 & 0.924 & 0.067 & 0.009 & 1 \\
\hline 27 & STH366 & 0.001 & 0.999 & 0 & 2 \\
\hline 28 & Suweren & 0 & 1 & 0 & 2 \\
\hline 29 & DM2495/10 & 0.25 & 0.239 & 0.51 & 3 \\
\hline 30 & OLYMPIC & 0.417 & 0.398 & 0.185 & 1 \\
\hline 31 & DM3084/10 & 0.115 & 0.109 & 0.776 & 3 \\
\hline 32 & STH35014 & 1 & 0 & 0 & 1 \\
\hline 33 & STH35031 & 0.926 & 0.072 & 0.001 & 1 \\
\hline 34 & STH373 & 0.001 & 0.998 & 0.001 & 2 \\
\hline 35 & J09038/14 & 0,001 & 0.686 & 0.313 & 2 \\
\hline 36 & DB07022/1 & 0.104 & 0.487 & 0.408 & $2 / 3$ \\
\hline 37 & DM2685/10 & 0.001 & 0 & 0.999 & 3 \\
\hline 38 & STH33562 & 0.001 & 0 & 0.999 & 3 \\
\hline 39 & STH35017 & 0.999 & 0 & 0 & 1 \\
\hline 40 & STH33570 & 0.404 & 0 & 0.595 & 3 \\
\hline 41 & STH497 & 0.086 & 0.619 & 0,295 & 2 \\
\hline 42 & J09046/20 & 0,02 & 0.253 & 0.727 & 3 \\
\hline 43 & DM4474/11 & 0,002 & 0.006 & 0.992 & 3 \\
\hline 44 & DB07022/11 & 0.315 & 0.0.326 & 0.36 & $1 / 2 / 3$ \\
\hline 45 & STH34999 & 1 & 0 & 0 & 1 \\
\hline 46 & STH35019 & 0.911 & 0 & 0.089 & 1 \\
\hline 47 & STH33575 & 0 & 0 & 0.999 & 3 \\
\hline
\end{tabular}

Table 3 (continued)

No. Genotype Probability that the genotype Subpopulation belongs to subpopulation

\begin{tabular}{llllll}
\cline { 3 - 5 } & & $1 \mathrm{~S}(\mathrm{p})$ & $2 \mathrm{~S}(\mathrm{p})$ & $3 \mathrm{~S}(\mathrm{p})$ & \\
\hline 48 & STH464 & 0.009 & 0.66 & 0.331 & 2 \\
49 & SOLDO & 0.439 & 0.21 & 0.351 & 1 \\
50 & DB07080/6 & 0.296 & 0.055 & 0.649 & 3 \\
51 & STH35003 & 1 & 0 & 0 & 1 \\
52 & STH35020 & 1 & 0 & 0 & 1 \\
53 & STH33598 & 0.091 & 0 & 0.909 & 3 \\
54 & STH472 & 0.161 & 0.838 & 0 & 2
\end{tabular}

55

56

57

58

59

60

61

62

63

64

65

66

67

68

69

70

71

72

73

74

75

76

77

78

79

80

81

82

83

84

85

86

87

88

89

90

91

92

93

DM4690/1

J08060/2

0

J09003/14

0.004

1

0.219

$0 \quad 2$

STH33846

0.185

0.332

$0.777 \quad 3$

STH34936

$0.466 \quad 0.259$

0.482

STH34874

0.001

0.27

STH156

0.379

0

$0.999 \quad 3$

DB07117/4

0.431

0.563

0.6213

J08060/16

0.058

$0.006 \quad 2$

J09008/3

0.01

STH33320

0.005

0.411

$0.531 \quad 3$

STH34984

0.3

STH34875

1

STH491

DM2632/10

0.124

0.21

$0.78 \quad 3$

J08062/3

0.562

J09011/14

0.006

0.323

$0.672 \quad 3$

STH33424

0.258

0.445

STH34985

STH34876

1

STH293

DM2968/10

0.373

0.001

0,198

0.4643

\section{J08084/3}

0.012

J09018/9

0.489

STH33425

0.385

0.011

STH34818

0.045

STH34878

0.356

STH294

J08005/19

0.002

0

0

0.475

0

$0.999 \quad 3$

$0.401 \quad 2$

0.186

$0.252 \quad 1$

$0.216 \quad 0.778 \quad 3$

$0.092 \quad 0.651 \quad 3$

0.387

$0.169 \quad 1$

J08084/20

0.195

0

0

0.998

$\begin{array}{ll}0 & 1\end{array}$

$0.627 \quad 3$

$0.001 \quad 2$

0.762

$0.226 \quad 2$

$\mathbf{0 . 5 1 1}$

o $1 / 2$

0.445

0.1692

0.498

$0.49 \quad 2$

0.194

$0.761 \quad 3$

0

0.6443

J09034/10

0.489

0.248

$0.75 \quad 3$

STH34838

0.111

0.17

0.6353

STH34819

0.067

0.511

0

0.8863

0.001

0.445

$0.488 \quad 2 / 3$

STH34880

0.398

0.165

0.8343

STH301

0.005

0

0.6013

J08008/17

0.001

0.239

$0.756 \quad 3$

J08085/6

0.001

0.585

$0.415 \quad 2$

J09043/3

0.571

$0.429 \quad 2$

0.9993

STH34851

0

0.001

0.6563

94

STH34821

0.293

0.061

0.6453 
Table 3 (continued)

\begin{tabular}{llllll}
\hline No. & Genotype & \multicolumn{3}{c}{$\begin{array}{l}\text { Probability that the genotype } \\
\text { belongs to subpopulation }\end{array}$} & Subpopulation \\
\cline { 3 - 5 } & & 1S (p) & 2 S (p) & $3 \mathrm{~S}(\mathrm{p})$ & \\
\hline 95 & STH34883 & 0.363 & 0 & 0.637 & 3 \\
96 & STH330 & 0 & 1 & 0 & 2 \\
97 & J08055/16 & 0 & 0.022 & 0.978 & 3 \\
98 & J08085/10 & 0.017 & 0.247 & 0.736 & 3 \\
99 & STH34991 & 0.999 & 0 & 0.001 & 1 \\
100 & STH34903 & 0.371 & 0 & 0.629 & 3 \\
101 & STH34822 & 0.439 & 0 & 0.561 & 3 \\
102 & STH34959 & 0.091 & 0.151 & 0.758 & 3 \\
103 & STH483 & 0.205 & 0.72 & 0.075 & 2 \\
104 & J08056/10 & 0.091 & 0.783 & 0.126 & 2 \\
105 & J08086/6 & 0.001 & 0.723 & 0.277 & 2 \\
106 & STH34441 & 0.001 & 0.538 & 0.461 & 2 \\
107 & STH34935 & 0.001 & 0 & 0.999 & 3 \\
108 & STH34839 & 0.385 & 0 & 0.615 & 3 \\
109 & STH34964 & 1 & 0 & 0 & 1 \\
\hline
\end{tabular}

Genotypes probably belonging to more than one subpopulation are indicated in bold

genotypes (according to the marker system only), respectively, but the second subpopulation consisted of the same number of both. The second possible reason of this correlation is the narrowing down of the set of DArTseq and SNP markers to those from the vicinity of already existing QTLs related to drought. However, out of three subpopulations revealed in this study there is none that is clearly the most or least tolerant in all aspects (physiological parameters measured) making it impossible to state that the population's structure results from drought tolerance or one/few drought tolerance-related traits directly. In most of the studies involving association mapping population's structure was established using markers of whole genome coverage (e.g., Jin et al. 2010; Chhatre et al. 2013; Gupta et al. 2014), even when the AM itself was not genome-wide (Harjes et al. 2008; Zheng et al. 2008; Holliday et al. 2010; Caniato et al. 2014). Yet, none of these studies aimed to complement and confirm results from a previous QTL study. In the light of the purpose of this study population's structure that is related to drought tolerance to a certain extent is understandable and even favorable. All in all the mapping population was selected to be as drought tolerance-related as possible to reveal more drought response-related chromosome regions.

Our results indicate that linkage group $2 \mathrm{H}$ contains the highest number of significant associations. The markers located near the $Q W C$.sthf- $2 H$ region flanked by the bPb8949 and bPb-1967 markers, as well as the Qqp.sthf-2H and QPSII.sthf-2H regions (Wójcik-Jagła et al. 2013) are mostly associated with chlorophyll $a$ fluorescence parameters. Chromosome $2 \mathrm{H}$ was confirmed as important for drought responses by Guo et al. (2008) based on changes in chlorophyll $a$ fluorescence parameters. They confirmed that chromosome $2 \mathrm{H}$ carries two QTL regions for chlorophyll $a$ fluorescence parameters. Other studies reported the presence of additional QTL regions for these parameters on barley chromosomes $3 \mathrm{H}, 4 \mathrm{H}, 5 \mathrm{H}$, and $6 \mathrm{H}$ (Guo et al. 2008; Wójcik-Jagła et al. 2013).

Chlorophyll fluorescence measurements are more sensitive than other data for determining plant stress responses, which is why we observed that most of the associations were for chlorophyll fluorescence parameters. This method can indirectly indicate the changes in photosynthetic performance induced by even subtle changes in water relations, nutrient availability, light, $\mathrm{CO}_{2}$, photoassimilate demand, and other relevant traits (Kalaji et al. 2014, 2016). The connections between changes in chlorophyll fluorescence and other more direct physiological parameters were easily detected in the present study. The results presented herein reveal the association of some markers with chlorophyll fluorescence parameters as well as with water relations-related parameters, especially on chromosomes $2 \mathrm{H}$ and $5 \mathrm{H}$. These chromosomes were previously determined as related to RWC (Teulat et al. 2003; Fan et al. 2015), WC (Wójcik-Jagła et al. 2013), and wilting score (Fan et al. 2015). Additionally, the markers associated with chlorophyll fluorescence parameters in the present study are located nearby markers within previously detected QTL regions for water relations (Wójcik-Jagła et al. 2013). Markers 32711359 and 100005565 from linkage group $2 \mathrm{H}$ are associated with chlorophyll fluorescence and correspond to markers $\mathrm{bPb}-8949$ and $\mathrm{bPb}-7160$ related to WC. Additionally, a similar pattern exists on linkage group $5 \mathrm{H}$ for markers 3397170,3929528 , and 5245116, which are located near marker bPb-8589. In this study, we detected markers associated with water relations neighboring markers bPb-1967 and bPb-1813, namely 7749450 and 3255497 on linkage groups $2 \mathrm{H}$ and $5 \mathrm{H}$, respectively. These markers are located within regions related to drought-induced changes to chlorophyll fluorescence.

A similar relationship exists for chlorophyll fluorescence and gas exchange parameters. Marker 3396302 on linkage group $2 \mathrm{H}$ is associated with transpiration efficiency, and is located near $( \pm 0.14 \mathrm{cM})$ bPb-6048 and bPb-6280, which are related to chlorophyll fluorescence parameters. Marker 3271910 on linkage group $3 \mathrm{H}$ is associated with $P_{\mathrm{n}}$ and $\Phi \mathrm{CO}_{2}$, and is mapped near $( \pm 0.14 \mathrm{cM}) \mathrm{bPb}-4645$, which is located within regions containing QTLs related to ABS/ CS and ET.

The region on chromosome $3 \mathrm{H}$ with markers 3272729 and bPb-0709 may be particularly valuable. These two markers are related to WUE and $P_{\mathrm{n}}$ in our present and previous study (Wójcik-Jagła et al. 2013). These parameters represent the ability of plants to remain highly productive under drought conditions. Genotypes with high $P_{n}$ and leaf WC 
Table 4 Markers associated with drought tolerance parameters in spring barley

\begin{tabular}{|c|c|c|c|c|c|c|c|c|}
\hline $\begin{array}{l}\text { DArTseq } \\
\text { name }\end{array}$ & $\begin{array}{c}\text { marker } \\
\text { type }\end{array}$ & $\begin{array}{l}\text { linkage } \\
\text { group }\end{array}$ & $\begin{array}{l}\text { position } \\
(\mathrm{cM})\end{array}$ & $\mathbf{P}$ & Add F & $\mathbf{R}^{2}(\%)$ & $\begin{array}{l}\text { physiological } \\
\text { parameter }\end{array}$ & $\begin{array}{c}\text { DArT } \\
\text { markers in } \\
\text { the vicinity } \\
\text { (position and } \\
\text { trait } \\
\text { according to } \\
\text { Wójcik- } \\
\text { Jagla et al. } \\
\text { 2013) }\end{array}$ \\
\hline 3271359 & $\begin{array}{l}\text { Silico } \\
\text { DArT }\end{array}$ & $2 \mathrm{H}$ & 114,09 & $6,85 \mathrm{E}-04$ & 12,29 & 10,63 & $\mathrm{TR}_{\mathrm{o}} / \mathrm{CS}_{\mathrm{m}}$ & $\begin{array}{c}\mathrm{bPb}-8949 \\
(112,32 \mathrm{cM}, \\
\mathrm{WC}) ; \mathrm{bPb}- \\
7160(113,88 \\
\mathrm{cM}, \mathrm{WC})\end{array}$ \\
\hline \multirow{4}{*}{100005565} & \multirow{4}{*}{ SNP } & \multirow{4}{*}{$2 \mathrm{H}$} & \multirow{4}{*}{114,09} & $4,88 \mathrm{E}-04$ & 13,05 & 11,27 & $\mathrm{ET}_{\mathrm{o}} / \mathrm{CS}_{\mathrm{o}}$ & \multirow{4}{*}{$\begin{array}{c}\text { bPb-8949 } \\
(112,32 \mathrm{cM} \text {, } \\
\text { WC); bPb- } \\
7160(113,88 \\
\mathrm{cM}, \mathrm{WC})\end{array}$} \\
\hline & & & & $6,91 \mathrm{E}-04$ & 12,31 & 10,98 & $\mathrm{ABS} / \mathrm{CS}_{\mathrm{m}}$ & \\
\hline & & & & $5,86 \mathrm{E}-04$ & 12,66 & 11,28 & $\mathrm{TR}_{\mathrm{o}} / \mathrm{CS}_{\mathrm{m}}$ & \\
\hline & & & & $3,39 \mathrm{E}-04$ & 13,83 & 12,11 & $\mathrm{ET}_{\mathrm{o}} / \mathrm{CS}_{\mathrm{m}}$ & \\
\hline 7749450 & SNP & $2 \mathrm{H}$ & 118,7 & $3,58 \mathrm{E}-04$ & 13,72 & 10,41 & WUE & $\begin{array}{c}\mathrm{bPb}-1967 \\
(117,97 \mathrm{cM}, \\
\left.\mathrm{WC}, \mathrm{DI}_{\alpha} / \mathrm{CS}\right)\end{array}$ \\
\hline \multirow{7}{*}{3986215} & \multirow{7}{*}{$\begin{array}{l}\text { Silico } \\
\text { DArT }\end{array}$} & \multirow{7}{*}{$2 \mathrm{H}$} & \multirow{7}{*}{141,01} & 2,59E-04 & 14,38 & 12,51 & $\mathrm{~F}_{\mathrm{v}} / \mathrm{F}_{\mathrm{m}}$ & \multirow{7}{*}{$\begin{array}{c}\mathrm{bPb}-1051 \mathrm{bK} \\
(141,64 \mathrm{cM}, \\
\left.\mathrm{q}_{\mathrm{p}}\right) ; \mathrm{bPb}- \\
0572(142,63 \\
\mathrm{cM}, \mathrm{RC} / \mathrm{CS})\end{array}$} \\
\hline & & & & $3,39 \mathrm{E}-04$ & 13,8 & 12,14 & $\mathrm{DI}_{0} / \mathrm{RC}$ & \\
\hline & & & & $2,93 \mathrm{E}-04$ & 14,12 & 12,49 & $\mathrm{RC} / \mathrm{CS}_{\mathrm{m}}$ & \\
\hline & & & & 4,31E-04 & 13,29 & 11,7 & $\mathrm{ABS} / \mathrm{CS}_{\mathrm{m}}$ & \\
\hline & & & & $1,89 \mathrm{E}-04$ & 15,07 & 13,07 & $\mathrm{TR}_{\mathrm{o}} / \mathrm{CS}_{\mathrm{m}}$ & \\
\hline & & & & $6,93 \mathrm{E}-05$ & 17,29 & 14,52 & $\mathrm{ET}_{\mathrm{o}} / \mathrm{CS}_{\mathrm{m}}$ & \\
\hline & & & & $5,51 \mathrm{E}-04$ & 12,77 & 11,33 & $\mathrm{PI}_{\mathrm{ABS}}$ & \\
\hline 3267111 & SNP & $2 \mathrm{H}$ & 146,92 & $8,28 \mathrm{E}-04$ & 11,9 & 10,29 & $\phi$ PSII & \multirow{4}{*}{$\begin{array}{c}\text { bPb-6048, } \\
\text { bPb-6280 } \\
(147,45 \mathrm{cM}, \\
\text { qp, } \phi \text { PSII }) ; \\
\text { bPb-9520, } \\
\text { bPb-7434 } \\
(148,16 \mathrm{cM}, \\
\left.\mathrm{q}_{\mathrm{p}}, \phi \mathrm{PSII}\right)\end{array}$} \\
\hline 100005532 & SNP & $2 \mathrm{H}$ & 147,11 & $9,02 \mathrm{E}-04$ & 11,76 & 10,77 & $\mathrm{TR}_{0} / \mathrm{RC}$ & \\
\hline 3396302 & $\begin{array}{l}\text { Silico } \\
\text { DArT }\end{array}$ & $2 \mathrm{H}$ & 147,31 & $2,83 \mathrm{E}-04$ & 14,14 & 9,4 & E & \\
\hline 3265531 & $\begin{array}{l}\text { Silico } \\
\text { DArT }\end{array}$ & $2 \mathrm{H}$ & 147,31 & $6,16 \mathrm{E}-04$ & 12,49 & 10,31 & $\mathrm{ET}_{\mathrm{o}} / \mathrm{CS}_{\mathrm{o}}$ & \\
\hline 3272729 & $\begin{array}{l}\text { Silico } \\
\text { DArT }\end{array}$ & $3 \mathrm{H}$ & 24,91 & $9,47 \mathrm{E}-05$ & 16,58 & 12,38 & WUE & $\begin{array}{c}\mathrm{bPb}-0709 \\
(25,28 \mathrm{cM} \\
\left.\mathrm{P}_{\mathrm{n}}, \mathrm{PI}\right)\end{array}$ \\
\hline 3273890 & SNP & $3 \mathrm{H}$ & 51,06 & 4,99E-04 & 12,97 & 10,6 & $\phi \mathrm{PSII} / \phi \mathrm{CO}_{2}$ & \multirow{3}{*}{$\begin{array}{c}\mathrm{bPb}-4645 \\
(51,77 \mathrm{cM} \text {, } \\
\mathrm{ABS} / \mathrm{CS}, \mathrm{ET})\end{array}$} \\
\hline \multirow{2}{*}{3271910} & Silico & \multirow{2}{*}{$3 \mathrm{H}$} & \multirow{2}{*}{51,63} & $3,05 \mathrm{E}-04$ & 14,01 & 12,08 & $P_{n}$ & \\
\hline & DArT & & & $3,05 \mathrm{E}-04$ & 14,01 & 12,08 & $\phi \mathrm{CO}_{2}$ & \\
\hline 3257590 & SNP & $4 \mathrm{H}$ & 43,34 & 1,97E-04 & 14,92 & 11,77 & $\phi \mathrm{PSII} / \phi \mathrm{CO}_{2}$ & $\begin{array}{c}\mathrm{bPb}-1408 \\
(43,34 \mathrm{cM}, \\
\left.\mathrm{q}_{\mathrm{p}}, \phi \mathrm{PSII}\right)\end{array}$ \\
\hline \multirow{2}{*}{4789498} & Silico & \multirow{2}{*}{$4 \mathrm{H}$} & \multirow{2}{*}{49,86} & $4,75 \mathrm{E}-04$ & 13,05 & 8,91 & $\mathrm{C}_{\mathrm{i}}$ & \multirow{2}{*}{-} \\
\hline & DArT & & & $7,86 \mathrm{E}-05$ & 16,94 & 11,77 & WUE & \\
\hline \multirow{2}{*}{3397016} & Silico & \multirow{2}{*}{$4 \mathrm{H}$} & \multirow{2}{*}{49,86} & $3,77 \mathrm{E}-04$ & 13,6 & 11,17 & $\mathrm{~g}_{\mathrm{s}}$ & \multirow[b]{2}{*}{ - } \\
\hline & DArT & & & $1,88 \mathrm{E}-04$ & 15,1 & 12,95 & $\phi \mathrm{PSII} / \phi \mathrm{CO}_{2}$ & \\
\hline 3272214 & $\begin{array}{l}\text { Silico } \\
\text { DArT }\end{array}$ & $4 \mathrm{H}$ & 49,86 & $8,36 \mathrm{E}-04$ & 11,87 & 10,02 & $\mathrm{ET}_{\mathrm{o}} / \mathrm{CS}_{\mathrm{o}}$ & - \\
\hline 3256824 & SNP & $4 \mathrm{H}$ & 50,99 & $1,66 \mathrm{E}-04$ & 15,28 & 11,51 & $\mathrm{~g}_{\mathrm{s}}$ & - \\
\hline & & & & $5,88 \mathrm{E}-04$ & 12,66 & 11,49 & $\mathrm{ABS} / \mathrm{CS}_{\mathrm{m}}$ & \\
\hline 3396503 & Silico & $4 \mathrm{H}$ & 51,2 & $5,47 \mathrm{E}-04$ & 12,81 & 11,63 & $\mathrm{TR}_{\mathrm{o}} / \mathrm{CS}_{\mathrm{m}}$ & - \\
\hline & & & & $6,51 \mathrm{E}-04$ & 12,44 & 11,27 & $\mathrm{ET}_{\mathrm{o}} / \mathrm{CS}_{\mathrm{m}}$ & \\
\hline 3258674 & SNP & $4 \mathrm{H}$ & 51,42 & $8,53 \mathrm{E}-04$ & 11,82 & 8,22 & $\mathrm{C}_{\mathrm{i}}$ & - \\
\hline 6437097 & SNP & $4 \mathrm{H}$ & 51,42 & $9,12 \mathrm{E}-04$ & 11,69 & 8,88 & WUE & - \\
\hline 3261200 & $\begin{array}{l}\text { Silico } \\
\text { DArT }\end{array}$ & $4 \mathrm{H}$ & 51,88 & $4,22 \mathrm{E}-04$ & 13,31 & 9,67 & WUE & - \\
\hline 3267008 & Silico & $4 \mathrm{H}$ & 5105 & $9,06 \mathrm{E}-04$ & 11,71 & 10,21 & $\mathrm{ABS} / \mathrm{CS}_{\mathrm{m}}$ & 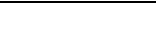 \\
\hline $520 / 000$ & DArT & $4 \Pi$ & ע & $8,23 \mathrm{E}-04$ & 11,91 & 10,37 & $\mathrm{TR}_{\mathrm{o}} / \mathrm{CS}_{\mathrm{m}}$ & - \\
\hline & & & & $2,78 \mathrm{E}-04$ & 14,26 & 12,3 & $\mathrm{ABS} / \mathrm{CS}_{0}$ & \\
\hline 3665232 & SNP & $4 \mathrm{H}$ & 52,34 & $1,25 \mathrm{E}-04$ & 16,01 & 13,97 & $\mathrm{DI}_{\mathrm{o}} / \mathrm{CS}_{\mathrm{o}}$ & - \\
\hline & & & & $2,78 \mathrm{E}-04$ & 14,26 & 12,3 & $\mathrm{DI}_{\mathrm{o}} / \mathrm{CS}_{\mathrm{m}}$ & \\
\hline 3986228 & $\begin{array}{l}\text { Silico } \\
\text { DArT }\end{array}$ & $4 \mathrm{H}$ & 52,44 & $1,18 \mathrm{E}-04$ & 16,05 & 12,6 & $\phi \mathrm{PSII} / \phi \mathrm{CO}_{2}$ & - \\
\hline 3266037 & $\begin{array}{l}\text { Silico } \\
\text { DArT }\end{array}$ & $4 \mathrm{H}$ & 52,66 & $1,04 \mathrm{E}-04$ & 16,37 & 11,99 & WUE & - \\
\hline 3263797 & SNP & $4 \mathrm{H}$ & 54.32 & 9,12E-04 & 11,69 & 10,12 & $\mathrm{TR}_{0} / \mathrm{RC}$ & - \\
\hline $3263 / 91$ & SNP & $4 \mathrm{H}$ & 54,32 & $9,09 \mathrm{E}-04$ & 11,69 & 10,19 & $\mathrm{PI}_{\mathrm{ABS}}$ & - \\
\hline
\end{tabular}


Table 4 (continued)

\begin{tabular}{|c|c|c|c|c|c|c|c|c|}
\hline $\begin{array}{l}\text { DArTseq } \\
\text { name }\end{array}$ & $\begin{array}{c}\text { marker } \\
\text { type }\end{array}$ & $\begin{array}{l}\text { linkage } \\
\text { group }\end{array}$ & $\begin{array}{l}\text { position } \\
(\mathrm{cM})\end{array}$ & $\mathbf{P}$ & Add F & $R^{2}(\%)$ & $\begin{array}{l}\text { physiological } \\
\text { parameter }\end{array}$ & $\begin{array}{c}\text { DArT } \\
\text { markers in } \\
\text { the vicinity } \\
\text { (position and } \\
\text { trait } \\
\text { according to } \\
\text { Wójcik- } \\
\text { Jagla et al. } \\
\text { 2013) }\end{array}$ \\
\hline & & & & $6,16 \mathrm{E}-04$ & 12,51 & 9,55 & WUE & \\
\hline 3255717 & SNP & $4 \mathrm{H}$ & 54,32 & $5,93 \mathrm{E}-05$ & 17,66 & 13,18 & WUE & - \\
\hline 3257131 & SNP & $4 \mathrm{H}$ & 54,6 & $2,88 \mathrm{E}-04$ & 14,12 & 6,97 & WC & - \\
\hline \multirow{2}{*}{3397170} & \multirow{2}{*}{ SNP } & \multirow{2}{*}{$5 \mathrm{H}$} & \multirow{2}{*}{43,02} & 7,49E-04 & 12,09 & 10,16 & $\mathrm{ABS} / \mathrm{CS}_{\mathrm{o}}$ & \multirow{5}{*}{$\begin{array}{c}\text { bPb-8589 } \\
(43,76 \mathrm{cM}, \\
\text { WC), bPb- } \\
3681(45,13 \\
\text { cM, EL) }\end{array}$} \\
\hline & & & & 7,49E-04 & 12,09 & 10,16 & $\mathrm{DI}_{\mathrm{o}} / \mathrm{CS}_{\mathrm{m}}$ & \\
\hline 3929528 & $\begin{array}{l}\text { Silico } \\
\text { DArT }\end{array}$ & $5 \mathrm{H}$ & 44,24 & 7,57E-04 & 12,09 & 10,7 & $\mathrm{TR}_{\mathrm{o}} / \mathrm{CS}_{\mathrm{m}}$ & \\
\hline \multirow{2}{*}{5245116} & \multirow{2}{*}{ SNP } & \multirow{2}{*}{$5 \mathrm{H}$} & \multirow{2}{*}{44,24} & $1,74 \mathrm{E}-04$ & 15,21 & 12,52 & $\mathrm{ABS} / \mathrm{CS}_{\mathrm{m}}$ & \\
\hline & & & & $1,84 \mathrm{E}-04$ & 15,09 & 12,44 & $\mathrm{TR}_{\mathrm{o}} / \mathrm{CS}_{\mathrm{m}}$ & \\
\hline 5249538 & SNP & $5 \mathrm{H}$ & 48,82 & $2,11 \mathrm{E}-05$ & 19,93 & 13,93 & WUE & \multirow{2}{*}{$\begin{array}{c}\mathrm{bPb}-8589 \\
(43,76 \mathrm{cM}, \\
\mathrm{WC}), \mathrm{bPb}- \\
3681(45,13 \\
\mathrm{cM}, \mathrm{EL})\end{array}$} \\
\hline 100002239 & SNP & $5 \mathrm{H}$ & 49,65 & $5,43 \mathrm{E}-05$ & 17,93 & 10,29 & RWC & \\
\hline \multirow[b]{2}{*}{3255497} & \multirow{2}{*}{ SNP } & \multirow{2}{*}{$5 \mathrm{H}$} & \multirow{2}{*}{147,14} & $9,21 \mathrm{E}-04$ & 11,66 & 9,99 & $\mathrm{ET}_{\mathrm{o}} / \mathrm{CS}_{\mathrm{m}}$ & \multirow{2}{*}{$\begin{array}{c}\mathrm{bPb}-1813 \\
(144,5 \mathrm{cM} \\
\mathrm{PI})\end{array}$} \\
\hline & & & & $1,31 \mathrm{E}-04$ & 15,83 & 8,2 & WC & \\
\hline \multirow{3}{*}{3985929} & \multirow{3}{*}{$\begin{array}{l}\text { Silico } \\
\text { DArT }\end{array}$} & \multirow{3}{*}{$6 \mathrm{H}$} & \multirow{3}{*}{60,06} & $9,35 \mathrm{E}-04$ & 11,65 & 10,35 & $\mathrm{~F}_{\mathrm{v}} / \mathrm{F}_{\mathrm{m}}$ & \multirow{3}{*}{$\begin{array}{c}\mathrm{bPb}-3230 \\
(60,62 \mathrm{cM} \\
\mathrm{EL})\end{array}$} \\
\hline & & & & 5,09E-04 & 12,93 & 11,23 & $\mathrm{ABS} / \mathrm{CS}_{\mathrm{m}}$ & \\
\hline & & & & $3,48 \mathrm{E}-04$ & 13,74 & 11,89 & $\mathrm{TR}_{\mathrm{o}} / \mathrm{CS}_{\mathrm{m}}$ & \\
\hline
\end{tabular}

$P$ critical value of the probability of association of marker with the trait, Add $F F$ value for the $F$ test for additive effect of allele, $R^{2}$ percentages of phenotypic variance explained by individual marker, $F_{V} / F_{m}$ performance index of energy trapped in PSII, $q_{P}$ photochemical light energy quenching coefficient, $\Phi P S I I$ quantum yield of electron transport in PSII, $A B S$ fluxes in the energy absorbed by PSII antennae, $C S_{m}$ excited leaf cross section (CS) at the $t$ of $F_{\mathrm{m}}, C S_{o}$ excited leaf cross section (CS) at $t=0, T R_{o}$ fluxes in the energy trapped in PSII reaction centers, $E T_{o}$ fluxes in the energy used for electron transport, $D I_{o}$ fluxes in the energy dissipated from PSII, $R C$ the maximum number of active reaction centers, $P I_{A B S}$ the overall PSII photochemical performance index for equal absorption, $E$ transpiration rate, $P_{n}$ net photosynthesis rate, $C_{i}$ intercellular $\mathrm{CO}_{2}$ concentration, $g_{s}$ stomatal conductivity, $\Phi C \mathrm{O}_{2}$ quantum yield of $\mathrm{CO}_{2}$ assimilation, WUE water use efficiency, $W C$ water content, $R W C$ relative water content, $E L$ electrolyte leakage, consistent results of the both studies are shaded

under drought conditions are more tolerant to water deficit stress (Rapacz et al. 2010b). These genotypes exhibit enhanced osmotic adjustment (Robredo et al. 2007), which is a crucial factor influencing the diversity in drought tolerance among barley accessions (Blum 1989).

In the present study some alleles have proven to be associated with more than one trait. This suggests that those traits are probably correlated. Chen and Lübberstedt (2010) distinguish two reasons for such a situation (genic pleiotropy)—-true pleiotropy or intragenic linkage of quantitative trait polymorphism (QTP) alleles. In both of those cases the effect can be either desirable or not with regard to the traits involved. If the marker associated with more than one trait is to be used in a breeding program it is crucial to investigate the effect of the allele on each of the traits (true pleiotropy) or the phase of QTP alleles (intragenic linkage) (Chen and Lübberstedt 2010).

One way of finding out if there is no negative linkage between the traits or repulsion of the alleles is the analysis of allele substitution effects (Würschum 2012). This kind of analysis can be used when the model of choice for the AM study is the mixed linear model (MLM) or its modifications that allow calculation of allele substitution effects (e.g., Liu et al. 2011; Würschum et al. 2011; Berger et al. 2013). However, even in the studies using models enabling such calculations, analysis of allele substitution effects is often not presented or discussed (e.g., Holliday et al. 2010; Sonah et al. 2015). In our study, the association mapping was performed using the GLM approach for the regions neighboring loci already known as involved in drought tolerance (Wójcik-Jagła et al. 2013). Neumann et al. (2011) in his study comparing GLM and MLM models for GWAS in bread wheat suggested that the GLM approach may be useful for comparing of the results with already known loci, especially as in some cases it is more sensitive than MLM (Yu et al. 2009).

Another approach to dissecting the nature of correlation of traits associated with one locus and the effect of the locus in question on each of them is performing big-scale field performance tests combined with identification of 
the presence/absence of the interesting marker loci. Such tests were performed for the markers used in this study for selection of the mapping population. We correlated the presence/absence of a marker with physiological traits and traits of agronomic importance (e.g., yield, protein content, height, etc.) (data not shown). This procedure, preceded by the necessary step of marker conversion (Fiust et al. 2015), can be used also for the markers associated with the most important physiological traits from this study.

Our results confirm some of the findings of an earlier QTL study on Polish spring barley materials (Wójcik-Jagła et al. 2013). The regions neighboring markers bPb-0572 and $3986215( \pm 1.62 \mathrm{cM})$ on linkage group $2 \mathrm{H}$ (both related to RC/CS), 3267111 and bPb-6048, as well as bPb6280 from QPSII.sthf- $2 H$ ( $\pm 0.53 \mathrm{cM}$; related to ФPSII) verify that the results from published studies involving traditional QTL mapping can be compared with association mapping results even for different groups of plant materials. Additionally, these are examples of identical parameters that overlapped in two studies. However, other parameters that might differ describe the same processes and essentially provide the same information regarding the conditions of drought-stressed plants. For example, the association of marker 7749450 with WUE in the present study confirms the importance of the chromosome $2 \mathrm{H}$ region in the control of plant water relations in drought. Markers bPb-1967 ( $\pm 1.27 \mathrm{cM})$, bPb-7160 $( \pm 4.82 \mathrm{cM})$, and bPb-8949 $( \pm 6.38 \mathrm{cM})$ were mapped within a QTL region responsible for changes in leaf WC during drought stress. Furthermore, our data confirm that association mapping is useful for increasing the density of existing QTL maps without recreated mapping populations. Our study also reveals that the traditional biparental QTL mapping and association mapping results can be complementary when the analyses are conducted using materials from the same gene pool.

Author contribution statement MWJ and AF contributed to all the experimental process, data analysis and results interpretation, as well as paper preparing. JK coordinated phenotyping experiment and contributed to phenotyping data analysis. MR coordinated experimental process and contributed to the preparing of the final manuscript version.

\footnotetext{
Acknowledgements This study was supported by the National Centre for Research and Development (Poland), Project GENMARK (PBS1/ A8/1/2012).
}

\section{Compliance with ethical standards}

Conflict of interest On behalf of all authors, the corresponding author states that there is no conflict of interest.
Human and animals rights statement This article does not contain any studies with human participants or animals performed by any of the authors.

Open Access This article is distributed under the terms of the Creative Commons Attribution 4.0 International License (http://creativecommons.org/licenses/by/4.0/), which permits unrestricted use, distribution, and reproduction in any medium, provided you give appropriate credit to the original author(s) and the source, provide a link to the Creative Commons license, and indicate if changes were made.

\section{References}

Agarwal M, Shrivastava N, Padh H (2008) Advances in molecular techniques and their applications in plant sciences. Plant Cell Rep 27:617-631

Alsop BP, Farre A, Wenzl P, Wang JM, Zhou MX, Romagosa I, Kilian A, Steffenson BJ (2011) Development of wild barleyderived DArT markers and their integration into a barley consensus map. Mol Breeding 27:77-92

Barrs HD (1968) Determination of water deficits in water plant tissues. In: Kozlowski TT (ed) Water deficits and plant growth. Academic Press, New York, pp 235-368

Benjamini Y, Hochberg Y (1995) Controlling the false discovery rate: a practical and powerful approach to multiple testing. J R Stat Soc Ser B 57:289-300

Berger GL, Liu S, Hall MD, Brooks WS, Chao S, Muehlbauer GJ et al (2013) Marker-trait associations in virginia tech winter barley identified using genome-wide mapping. Theor Appl Genet 126:693-710

Blum A (1989) Osmotic adjustment and growth of barley genotypes under drought stress. Crop Sci 29:230-233

Brachi B, Faure N, Horton M, Flahauw E, Vazquez A, Nordborg M et al (2010) Linkage and association mapping of Arabidopsis thaliana flowering time in nature. PLoS Genet 6:e1000940

Bradbury PJ, Zhang Z, Kroon DE, Casstevens TM, Ramdos Y, Buckler ES (2007) TASSEL: software for association mapping of complex traits in diverse samples. Bioinformatics 23:2633-2635

Caniato FF, Hamblin MT, Guimaraes CT, Zhang Z, Schaffert RE, Kochian LV, Magalhaes JV (2014) Association mapping provides insights into the origin and the fine structure of the sorghum aluminum tolerance locus, AltSB. PLoS One 9:e87438

Cardon LR, Bell JI (2001) Association study designs for complex diseases. Nat Rev Genet 2:91-99

Chen Y, Lübberstedt T (2010) Molecular basis of trait correlations. Trends Plant Sci 15:454-461

Chhatre VE, Byram TD, Neale DB, Wegrzyn JL, Krutovsky KV (2013) Genetic structure and association mapping of adaptive and selective traits in the east Texas loblolly pine (Pinus taeda L.) breeding populations. Tree Genetics Genomes 9:1161-1178

Deng W, Nickle DC, Learn GH, Maust B, Mullins JI (2007) ViroBLAST: a stand-alone BLAST web server for flexible queries of multiple databases and user's datasets. Bioinformatics 23:2334-2336

Evanno G, Regnaut S, Goudet J (2005) Detecting the number of clusters of individuals using the software STRUCTURE: a simulation study. Mol Ecol 14:2611-2620

Famoso AN, Zhao K, Clark RT, Tung CW, Wright MH, Bustamante $\mathrm{C}$ et al (2011) Genetic architecture of aluminum tolerance in rice (Oryza sativa) determined through genome-wide association analysis and QTL mapping. PLoS Genet 7:e1002221

Fan Y, Shabala S, Ma Y, Xu R, Zhou M (2015) Using QTL mapping to investigate the relationships between abiotic stress tolerance 
(drought and salinity) and agronomic and physiological traits. BMC Genomics 16:43

Fan Y, Zhou G, Shabala S, Chen Z-H, Cai S, Li C, Zhou M (2016) Genome-wide association study reveals a new QTL for salinity tolerance in Barley (Hordeum vulgare L.). Front Plant Sci 7:946

Fiust A, Rapacz M, Wójcik-Jagła M, Tyrka M (2015) Development of DArT-based PCR markers for selecting drought-tolerant spring barley. J Appl Genet 56:299-309

Flint-Garcia S, Thornsberry J, Buckler E (2003) Structure of linkage disequilibrium in plants. Annu Rev Plant Biol 54:357-374

Forster BP, Ellis RP, Thomas WTB, Newton AC, Tuberosa R, This D, El-Enein RA, Bahri MH, Ben Salem M (2000) The development and application of molecular markers for abiotic stress tolerance in barley. J Exp Bot 51:19-27

Gawenda I, Thorwarth P, Günther T, Ordon F, Schmid KJ (2015) Genome-wide association studies in elite varieties of German winter barley using single-marker and haplotype-based methods. Plant Breed 134:28-39

Genty B, Briantais J-M, Baker NR (1989) The relationship between the quantum yield of photosynthetic electron transport and quenching of chlorophyll fluorescence. Biochim Biophys Acta 990:87-92

Guo P, Baum M, Varshney RK, Graner A, Grando S, Ceccarelli S (2008) QTLs for chlorophyll and chlorophyll fluorescence parameters in barley under post-flowering drought. Euphytica 163:203-214

Gupta S, Kumari K, Muthamilarasan M, Parida SK, Prasad M (2014) Population structure and association mapping of yield contributing agronomic traits in foxtail millet. Plant Cell Rep 33:881-893

Harjes CE, Rocheford TR, Bai L, Brutnell TP, Kandianis CB, Sowinski SG et al (2008) Natural genetic variation in lycopene epsilon cyclase tapped for maize biofortification. Science 319:330-333

Holliday JA, Ritland K, Aitken SN (2010) Widespread, ecologically relevant genetic markers developed from association mapping of climate-related traits in Sitka spruce (Picea sitchensis). New Phytol 188:501-514

Jin L, Lu Y, Xiao P, Sun M, Corke H, Bao J (2010) Genetic diversity and population structure of a diverse set of rice germplasm for association mapping. Theor Appl Genet 121:475-487

Kalaji HM, Schansker G, Ladle RJ, Goltsev V, Bosa K, Allakhverdiev SI et al (2014) Frequently asked questions about in vivo chlorophyll fluorescence: practical issues. Photosynth Res 122:121-158

Kalaji HM, Schansker G, Brestic M, Bussotti F, Calatayud A, Ferroni L et al (2016) Frequently asked questions about chlorophyll fluorescence, the sequel. Photosynth Res. doi:10.1007/ s11120-016-0318-y

Korte A, Farlow A (2013) The advantages and limitations of trait analysis with GWAS: a review. Plant Methods 9:29

Kraakman ATW, Niks RE, Van den Berg PMMM, Stam P, Van Eeuwijk FA (2004) Linkage disequilibrium mapping of yield and yield stability in modern spring Barley cultivars. Genetics 168:435-446

Liu W, Gowda M, Steinhoff J, Maurer HP, Würschum T, Longin CFH et al (2011) Association mapping in an elite maize breeding population. Theor Appl Genet 123:847

Mackay I, Powell W (2007) Methods for linkage disequilibrium mapping in crops. Trends Plant Sci 12:57-63

Massman J, Cooper B, Horsley R, Neate S, Dill-Macky R, Chao S, Dong Y, Schwarz P, Muehlbauer GJ, Smith KP (2011) Genomewide association mapping of Fusarium head blight resistance in contemporary barley breeding germplasm. Mol Breeding 27:439-454

McMullen MD, Kresovich S, Sanchez Villeda H, Bradbury P, Li H, Sun Q et al (2009) Genetic properties of the maize nested association mapping population. Science 325:737-740

Meuwissen THE, Karlsen A, Lien S, Olsaker I, Goddard ME (2002) Fine mapping of a quantitative trait locus for twinning rate using combined linkage and linkage disequilibrium mapping. Genetics 161:373-379

Myles S, Peiffer J, Brown PJ, Ersoz ES, Hang Z, Costich DE, Buckler ES (2009) Association mapping: critical considerations shift from genotyping to experimental design. Plant Cell 21:2194-2202

Neumann K, Kobiljski B, Denčić S, Varshney RK, Börner A (2011) Genome-wide association mapping: a case study in bread wheat (Triticum aestivum L.). Mol Breeding 27:37-58

Nordborg M, Weigel D (2008) Next-generation genetics in plants. Nature 456:720-723

Porras-Hurtado L, Ruiz Y, Santos C, Phillips C, Carracedo A, Lareu MV (2013) An overview of Structure: applications, parameter settings, and supporting software. Front Genet 4:98

Pritchard JK, Stephens M, Rosenberg NA, Donnelly P (2000) Association mapping in structured populations. Am J Hum Genet 67:170-181

Purcell S, Cherny SS, Sham PC (2003) Genetic power calculation: design of linkage and association genetic mapping studies of complex traits. Bioinformatics 19:149-150

Rapacz M, Kościelniak J, Jurczyk B, Adamska A, Wójcik M (2010a) Different patterns of physiological and molecular response to drought in seedlings of malt- and feed-type Barleys (Hordeum vulgare). J Agron Crop Sci 196:9-19

Rapacz M, Tyrka M, Gut M, Mikulski W (2010b) Associations of PCR markers with freezing tolerance and photosynthetic acclimation to cold in winter barley. Euphytica 175:293-301

Robredo A, Pérez-López U, de la Maza HS, González-Moro B, Lacuesta M, Mena-Petite A, Muñoz-Rueda A (2007) Elevated $\mathrm{CO}_{2}$ alleviates the impact of drought on barley improving water status by lowering stomatal conductance and delaying its effects on photosynthesis. Environ Exp Bot 59:252-263

Roy JK, Smith KP, Muehlbauer GJ, Chao S, Close TJ, Steffenson BJ (2010) Association mapping of spot blotch resistance in wild barley. Mol Breeding 26:243

Shindo C, Aranzana MJ, Lister C, Baxter C, Nicholls C et al (2005) Role of FRIGIDA and FLOWERING LOCUS $\mathrm{C}$ in determining variation in flowering time of Arabidopsis. Plant Physiol 138:1163-1173

Sonah H, O’Donoughue L, Cober E, Rajcan I, Belzile F (2015) Identification of loci governing eight agronomic traits using a GBSGWAS approach and validation by QTL mapping in soya bean. Plant Biotechnol J 13:211-221

Stracke S, Haseneyer G, Veyrieras JB, Geiger HH, Sauer S, Graner A, Piepho HP (2009) Association mapping reveals gene action and interactions in the determination of flowering time in barley. Theor Appl Genet 118:259-273

Strasser RJ, Srivatava A, Tsimilli-Michael M (2000) The fluorescence transient as tool to characterize and screen photosynthetic samples. In: Yunus M, Pathre U, Mohanty P (eds) Probing photosynthesis: mechanism, regulation and adaptation. Taylor and Francis, Bristol, pp 445-483

Szúcs P, Blake VC, Bhat PR, Chao S, Close TJ, Cuesta-Marcos A, Muehlbauer GJ, Ramsay L, Waugh R, Hayes PM (2009) An integrated resource for barley linkage map and malting quality QTL alignment. Plant Genome 2:134-140

Teulat B, Zoumarou-Wallis N, Rotter B, Salem MB, Bahri H, This D (2003) QTL for relative water content in field-grown barley and their stability across Mediterranean environments. Theor Appl Genet 108:181-188

Varshney RK, Paulo MJ, Grando S, van Eeuwijk FA, Keizer LCP, Guo P, Ceccarelli S, Kilian A, Baum M, Graner A (2012) Genome wide association analyses for drought tolerance related traits in barley (Hordeum vulgare L.). Field Crop Res 126:171-180

Visioni A, Tondelli A, Francia E, Pswarayi A, Malosetti M, Russell J, Thomas W, Waugh R, Pecchioni N, Romagosa J, Comadran J 
(2013) Genome-wide association mapping of frost tolerance in barley (Hordeum vulgare L.). BMC Genomics 14:424

Wójcik-Jagła M, Rapacz M, Tyrka M, Kościelniak J, Crissy K, Żmuda K (2013) Comparative QTL analysis of early short-time drought tolerance in Polish fodder and malting spring barleys. Theor Appl Genet 126:3021-3034

Wu R, Zeng Z-B (2001) Joint linkage and linkage disequilibrium mapping in natural populations. Genetics 157:899-909

Würschum T (2012) Mapping QTL for agronomic traits in breeding populations. Theor Appl Genet 125:201-210

Würschum T, Maurer HP, Kraft T, Janssen G, Nilsson C, Reif JC (2011) Genome-wide association mapping of agronomic traits in sugar beet. Theor Appl Genet 123:1121

Yu J, Holland JB, McMullen MD, Buckler ES (2008) Genetic design and statistical power of nested association mapping in maize. Genetics 178:539-551
Yu J, Zhang Z, Zhu C, Tabanao DA, Pressoir G, Tuinstra MR, Kresovich S, Todhunter RJ, Buckler ES (2009) Simulation appraisal of the adequacy of number of background markers for relationship estimation in association mapping. Plant Genome 2:63-77

Zhao K, Tung CW, Eizenga GC, Wright MH, Liakat Ali M, Price AH, Norton GJ, Islam MR, Reynolds A, Mezey J, McClung AM, Bustamante CD, McCouch SR (2011) Genome-wide association mapping reveals rich genetic architecture of complex traits in Oryza sativa. Nat Commun. doi:10.1038/ncomms 1467

Zheng P, Allen WB, Roesler K, Williams ME, Hang S et al (2008) A phenylalanine in DGAT is a key determinant of oil content and composition in maize. Nat Genet 40:367-372

Zhu C, Gore M, Buckler ES, Yu J (2008) Status and prospects of association mapping in plants. Plant Genome 1:5-20 